\section{A new opportunity in regenerative medicine}

Of note, BMP2 enhances collagen production by canine tenocytes (12) and has been used to enhance tendon-bone integration in canine disease models (13). In this robustly validated preclinical model, surgical technique and postoperative physical therapy can be used to assess functional outcome and biomechanical strength (1) - the hallmarks of tendon repair that must be addressed in future studies. Immunologic and vascularization responses that influence the formation of fibrous adhesions may also be augmented by programmed neotendon cells and thus hamper restoration of function (14). Given that multipotent mesenchymal progenitors resembling $\mathrm{C} 3 \mathrm{H} 10 \mathrm{~T} 1 / 2$ cells can be isolated from tissues such as adipose (15) and skeletal muscle (16), engineered autografts might be best explored in canine models of tendon injury repair to minimize the deleterious immune responses; such responses may limit healing, biomechanical strength, and restoration of function. Nevertheless, the novel results reported here by Hoffmann et al. (5) add to the accumulating evidence that proliferating, multipotent mesenchymal progenitor cells can be programmed to yield yet another cell type
- the tenocyte - which may be potentially useful in cell-based therapeutic approaches to musculoskeletal injuries (1).

Address correspondence to: Dwight A. Towler, Department of Internal Medicine, Division of Bone and Mineral Diseases, Washington University School of Medicine, Barnes-Jewish North Campus Box 8301, 660 South Euclid Avenue, St. Louis, Missouri 63110, USA. Phone: (314) 454-7434; Fax: (314) 454-8434; E-mail: dtowler@im.wustl.edu.

1. Boyer, M.I., Goldfarb, C.A., and Gelberman, R.H. 2005. Recent progress in flexor tendon healing. The modulation of tendon healing with rehabilitation variables. J. Hand Ther. 18:80-85; quiz 86.

2. Fenwick, S.A., Hazleman, B.L., and Riley, G.P. 2002. The vasculature and its role in the damaged and healing tendon. Arthritis Res. 4:252-260.

3. Brent, A.E., Schweitzer, R., and Tabin, C.J. 2003. A somitic compartment of tendon progenitors. Cell. 113:235-248

4. Wolfman, N.M., et al. 1997. Ectopic induction of tendon and ligament in rats by growth and differentiation factors 5,6 , and 7 , members of the TGF- $\beta$ gene family. J. Clin. Invest. 100:321-330.

5. Hoffmann, A., et al. 2006. Neotendon formation induced by manipulation of the Smad8 signalling pathway in mesenchymal stem cells. J. Clin. Invest. 116:940-952. doi:10.1172/JCI22689.

6. Cheng, S.L., Shao, J.S., Charlton-Kachigian, N., Loewy, A.P., and Towler, D.A. 2003. MSX2 promotes osteogenesis and suppresses adipogenic differentiation of multipotent mesenchymal progenitors. J. Biol. Chem. 278:45969-45977.

7. Jasuja, R., et al. 2005. Tetrahydrogestrinone is an androgenic steroid that stimulates androgen receptor-mediated, myogenic differentiation in C3H10T1/2 multipotent mesenchymal cells and promotes muscle accretion in orchidectomized male rats. Endocrinology. 146:4472-4478.

8. Massague, J., Seoane, J., and Wotton, D. 2005. Smad transcription factors. Genes Dev. 19:2783-2810.

9. Yamamoto, N., et al. 1997. Smad1 and smad5 act downstream of intracellular signalings of BMP-2 that inhibits myogenic differentiation and induces osteoblast differentiation in $\mathrm{C} 2 \mathrm{C} 12$ myoblasts. Biochem. Biophys. Res. Commun. 238:574-580.

10. Wang, Q.W., Chen, Z.L., and Piao, Y.J. 2005. Mesenchymal stem cells differentiate into tenocytes by bone morphogenetic protein (BMP) 12 gene transfer. J. Biosci. Bioeng. 100:418-422.

11. Nakayama, T., et al. 1998. Xenopus Smad8 acts downstream of BMP-4 to modulate its activity during vertebrate embryonic patterning. Development. 125:857-867.

12. Thomopoulos, S., Harwood, F.L., Silva, M.J., Amiel, D., and Gelberman, R.H. 2005. Effect of several growth factors on canine flexor tendon fibroblast proliferation and collagen synthesis in vitro. J. Hand Surg. (Am.). 30:441-447.

13. Martinek, V., et al. 2002. Enhancement of tendon-bone integration of anterior cruciate ligament grafts with bone morphogenetic protein-2 gene transfer: a histological and biomechanical study. J. Bone Joint Surg. Am. 84:1123-1131.

14. Bidder, M., Towler, D.A., Gelberman, R.H., and Boyer, M.I. 2000. Expression of mRNA for vascular endothelial growth factor at the repair site of healing canine flexor tendon. J. Orthop. Res. 18:247-252.

15. Zuk, P.A., et al. 2002. Human adipose tissue is a source of multipotent stem cells. Mol. Biol. Cell. 13:4279-4295.

16. Lee, J.Y., et al. 2000. Clonal isolation of musclederived cells capable of enhancing muscle regeneration and bone healing. J. Cell Biol. 150:1085-1100.

\title{
A new cardiac MASTer switch for the renin-angiotensin system
}

\author{
Thu H. Le and Thomas M. Coffman
}

Division of Nephrology, Department of Medicine, Duke University and Durham VA Medical Centers, Durham, North Carolina, USA.

\begin{abstract}
The aspartyl protease renin was first isolated from the kidney by Tigerstedt more than a century ago. In the kidney, renin secretion is tightly linked to sodium intake and renal perfusion pressure, reflecting the important role of the renin-angiotensin system (RAS) in controlling body fluid volume and blood pressure. The study by Mackins et al. in this issue of the JCI describes a novel source of renin: the mast cell (see the related article beginning on page 1063). This discovery suggests a distinct pathway for activation of the RAS that may have a particular impact on the pathogenesis of chronic tissue injury as well as more acute pathology such as arrhythmias in the heart.
\end{abstract}

Nonstandard abbreviations used: ACE, angiotensinconverting enzyme; JG, juxtaglomerular; RAS, reninangiotensin system.

Conflict of interest: The authors have declared that no conflict of interest exists.

Citation for this article: J. Clin. Invest. 116:866-869 (2006). doi:10.1172/JCI28312.

\section{Separate renin-angiotensin systems} in the circulation and in tissues

The renin-angiotensin system (RAS) is a hormone system in which the substrate protein angiotensinogen is sequentially cleaved by peptidases, renin and angiotensin-converting enzyme (ACE), to form the biologically active octapeptide angiotensin II (Figure 1). A substantial excess of angiotensinogen is present in serum, and ACE is ubiquitous in the endothelium and plasma (1). Accordingly, in the bloodstream, the amount of renin is the rate-limiting step determining the level of angiotensin II and thus the activity of the system.

The primary source of renin in the circulation is the kidney, where its expression and secretion are tightly regulated at the juxtaglomerular (JG) apparatus by 2 distinct mechanisms: a renal baroreceptor $(2,3)$ and sodium chloride delivery to the macula densa $(4,5)$. Through these sensing mechanisms, levels of renin in plasma can be incrementally titrated in response 

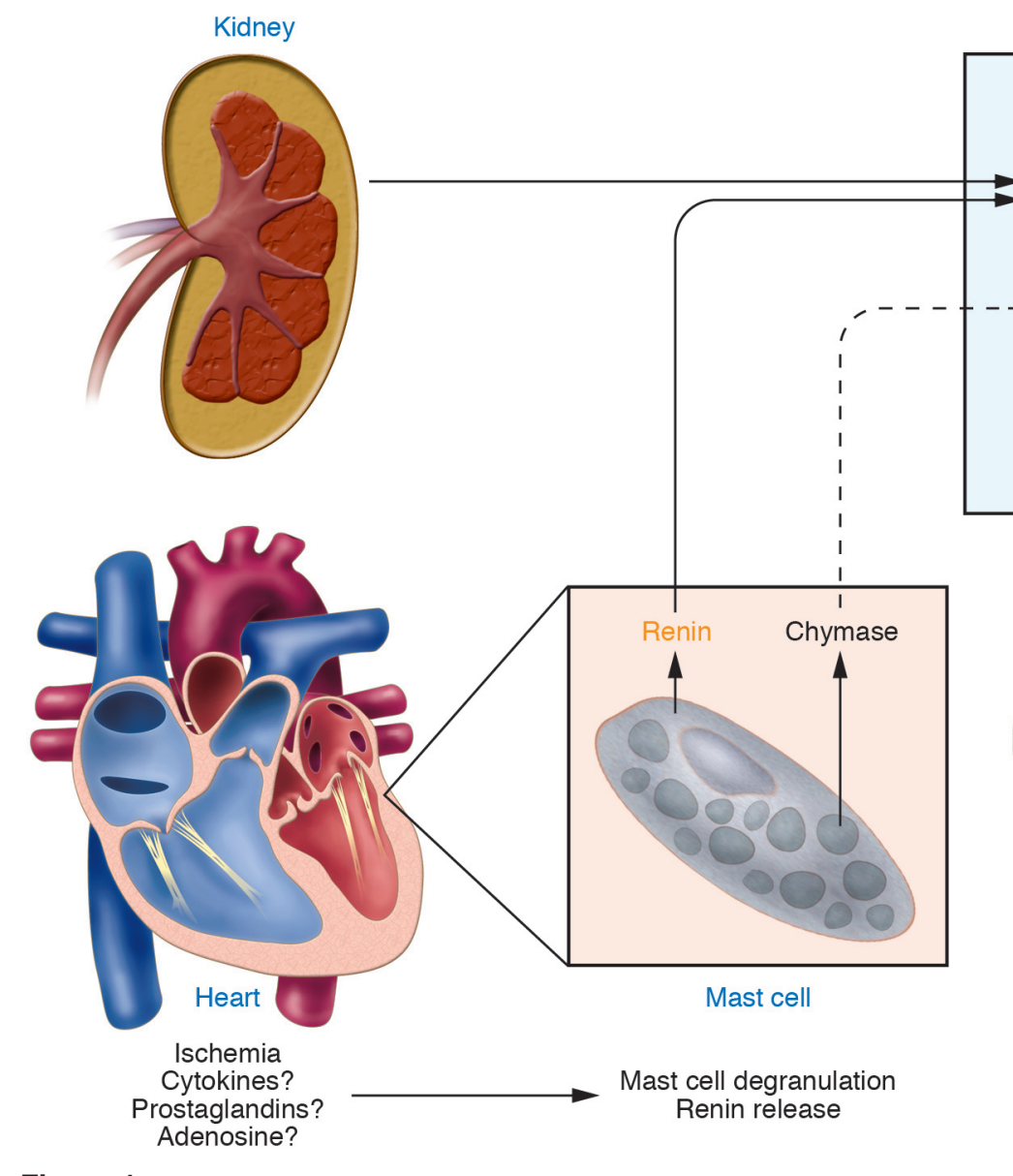

(1)

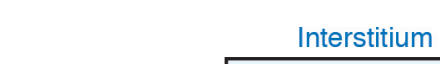

\section{ACE}

7

Angiotensin II

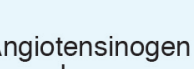

|

Renin

Angiotensin I
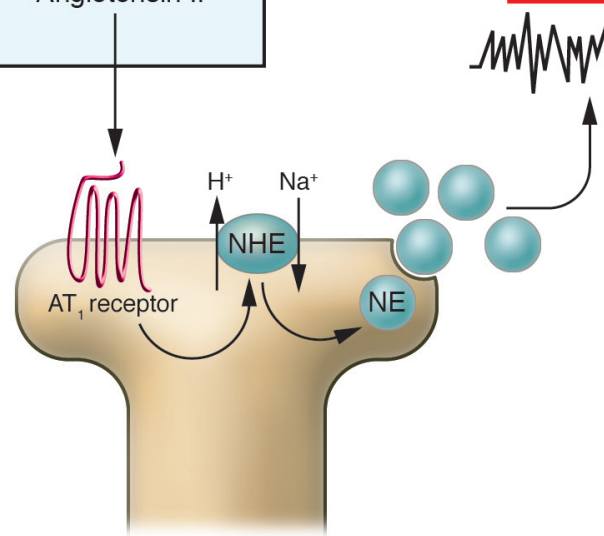

Synaptic nerve terminal

Cardiac arrhythmia

Figure 1

Production of renin by cardiac mast cells represents a novel mechanism for regulating the RAS. In this issue of the $J C I$, Mackins, Levi, and associates show that ischemia of the heart triggers renin release by cardiac mast cells, resulting in activation of the RAS (11). The consequent production of angiotensin II stimulates angiotensin II receptor, type 1 (AT $\left.T_{1}\right)$ in sympathetic nerve terminals, causing release of norepinephrine (NE) and generation of cardiac arrhythmias. These studies indicate that resident mast cells in the heart and perhaps other organs, upon appropriate stimulation, are capable of producing ample quantities of renin to activate the RAS locally and thereby modulate organ function. This pathway is likely to be regulated by factors linked to inflammation and injury that are quite different from those controlling renin release at the JG apparatus of the kidney. $\mathrm{NHE}, \mathrm{Na}^{+} / \mathrm{H}^{+}$exchanger.

to changes in blood pressure and salt balance. These regulatory principles provide a basis for many of the physiological characteristics of the RAS. Yet there appears to be additional complexity in the system. For example, in the broad population of patients with hypertension, diabetes, and cardiovascular disease, pharmacological antagonists of the RAS lower blood pressure and prevent end-organ damage even in the absence of overt elevation of plasma renin levels.

In response to these apparent discrepancies, the concept was articulated some years ago that individual tissues might have their own local RASs, which could be regulated independently of the circulating system (6). This theory is supported by studies demonstrating expression of
RAS genes in a variety of key target organs, including the heart and brain $(7,8)$. Moreover, control of RAS gene expression has been found to differ significantly among organs (9), indicating a potential basis for autonomy of these tissue systems.

\section{Mast cells as a source of renin in peripheral tissues}

Although expression of angiotensinogen, ACE, and angiotensin receptors has been clearly demonstrated in a variety of organ systems (7), it has been more difficult to convincingly document physiologically relevant expression of renin outside the kidney. This has presented a challenge to the concept of complete and autonomous RASs in individual tissues. Studies by Mackins, Levi, and colleagues indicating that mast cells generate and secrete renin $(10,11)$ may provide a solution to this problem. In a previous article, these authors reported that mast cells express renin mRNA and contain significant quantities of renin protein, likely within secretory granules (10). When degranulation of the mast cells was induced, renin derived from mast cells specifically and efficiently converted angiotensinogen to angiotensin I (10). Using an isolated, perfused heart preparation, they have now, in this issue of the JCI, extended the previous studies by showing that release of renin from cardiac mast cells causes local formation of angiotensin in sufficient amounts to cause pathophysiological consequences including release of norepinephrine and generation of arrhythmias (11) (Figure 1). Taken together, these studies 
provide compelling evidence that resident mast cells in the heart and perhaps other organs, upon appropriate stimulation, are capable of generating ample quantities of renin to activate the RAS locally and thereby affect organ function.

\section{How might renin release be regulated in mast cells?}

Mast cells are derived from hematopoietic progenitors that migrate into all vascularized tissues, where they mature and reside, constituting an important effector limb of the inflammatory response (12). Upon activation, mast cells undergo complex biochemical and morphological alterations culminating in the release of a wide range of mediators from cytoplasmic granules. The work of Mackins, Levi, and associates indicates that renin is one of the mediators released with degranulation $(10,11)$. However, the precise basis for control of renin in mast cells is not clear, and this will be a critical area for future research. It is notable that renin is also stored in secretory granules within renal JG cells, where it is released through degranulation and exocytosis $(1,13)$. Yet despite the apparent similarities in the intracellular machinery for handling renin, the regulatory factors and pathways controlling renin in JG cells and mast cells are likely to be quite different.

The prototypical pathway for mast cell activation and degranulation involves engagement of FceRI receptors by antibody or immune complexes, with activation of phospholipase $\mathrm{C}$ and increases in intracellular calcium concentration (12). By contrast, exocytosis of renin granules in JG cells is linked to $G_{s}$ protein signaling and increases in intracellular cAMP levels (14). Mackins et al. now show that ischemia in isolated guinea pig hearts perfused with a blood-free solution is sufficient to stimulate cardiac mast cells to release renin (11). Thus, cardiac mast cells appear to be capable of secreting renin through a process that is independent of typical antibody-receptor triggering. While the specific factors controlling renin release by mast cells have not yet been identified, a number of stimuli that are potentially relevant to cardiovascular disease can modulate mast cell degranulation, including cytokines, prostaglandins, adenosine, and LPS (12, $15,16)$. Thus, it is likely that the pathway controlling renin release in tissues will be linked to environmental cues associated with inflammation and injury (Figure 1).

\section{Other contributions of mast cells to the RAS}

Although the finding that mast cells are a source of renin in peripheral tissues is novel (11), previous studies have suggested a role for cardiac mast cells in the RAS. It has been long recognized that there are alternate pathways for converting angiotensin I to angiotensin II that do not require ACE. A clinical consequence of these pathways is seen in patients who take ACE inhibitors chronically, where incomplete suppression of angiotensin II levels in plasma is often observed (17). ACE-independent angiotensin II formation was found to be particularly robust in the heart, and this activity was eventually assigned to a serine proteinase belonging to the chymase family (18). Furthermore, the major cellular source of this chymase is the mast cell (19) (Figure 1). With the discovery of renin in mast cells, it is now apparent that these cells have the complete enzymatic machinery to produce angiotensin II from angiotensinogen. Why would mast cells have this capacity? While the answer to the question is not clear, one function of mast cells is immunoregulation (12). As angiotensin II itself can modulate inflammation and immunity (20), one purpose for renin generated by mast cells may be immunomodulation through regulating the activity of the RAS in the immune system.

\section{Mast cells and cardiovascular disease}

The strongest evidence for a connection between mast cells and human disease is in the area of allergic diseases and asthma. However, mast cells may also be involved in a spectrum of inflammatory diseases ranging from multiple sclerosis, migraine, inflammatory arthritis, atopic dermatitis, interstitial cystitis, irritable bowel syndrome, and coronary inflammation (21). In the heart, mast cells accumulate in coronary plaques at the site of plaque rupture in myocardial infarction $(22,23)$, and the number of degranulated mast cells in the adventitia surrounding ruptured plaques is increased in infarctrelated coronary arteries (24). In these circumstances, release of renin by mast cells and subsequent activation of the RAS in the heart might contribute directly to the pathogenesis of cardiac injury. Consistent with this idea, a recent study indicates a direct role for mast cells in promoting left-ventricular dysfunction in a model of congestive heart failure (25).
In summary, the finding that mast cells produce renin raises the possibility of an alternate mechanism for regulation of the RAS, controlled by inflammatory mechanisms likely to be quite different from those that regulate renin release by the kidney. Moreover, this mast cell-dependent pathway for renin production may be linked to local activation of the RAS in the heart, and perhaps other organs, potentially providing a distinct control for angiotensin II generation in peripheral tissues. A critical question, which can be tested with available tools, is whether this alternative pathway for RAS activation plays any major role in physiology or disease pathogenesis. If so, this pathway would represent a tangible link between inflammation, the RAS, and cardiovascular disease.

Address correspondence to: Thomas M. Coffman, Building 6/Nephrology (111I), VA Medical Center, 508 Fulton Street, Durham, North Carolina 27705, USA. Phone: (919) 286-6947; Fax: (919) 286-6879; E-mail: tcoffman@acpub.duke.edu.

1. Peach, M.J. 1977. Renin-angiotensin system: biochemistry and mechanisms of action. Physiol. Rev. 57:313-370.

2. Bock, H.A., Hermle, M., Brunner, F.P., and Thiel, G. 1992. Pressure dependent modulation of renin release in isolated perfused glomeruli. Kidney Int. 41:275-280.

3. Carey, R.M., McGrath, H.E., Pentz, E.S., Gomez, R.A., and Barrett, P.Q. 1997. Biomechanical coupling in renin-releasing cells. J. Clin. Invest. 100:1566-1574

4. Bell, P.D., et al. 2003. Macula densa cell signaling involves ATP release through a maxi anion channel. Proc. Natl. Acad. Sci. U. S. A. 100:4322-4327.

5. Lorenz, J.N., Greenberg, S.G., and Briggs, J.P. 1993. The macula densa mechanism for control of renin secretion. Semin. Nephrol. 13:531-542.

6. Dzau, V.J. 1987. Implications of local angiotensin production in cardiovascular physiology and pharmacology. Am. J. Cardiol. 59:59A-65A.

7. Bader, M., et al. 2001. Tissue renin-angiotensin systems: new insights from experimental animal models in hypertension research. J. Mol. Med. 79:76-102.

8. Davisson, R.L. 2003. Physiological genomic analysis of the brain renin-angiotensin system. Am.J. Physiol. 285:R498-R511.

9. Dostal, D.E., and Baker, K.M. 1999. The cardiac renin-angiotensin system: conceptual, or a regulator of cardiac function? Circ. Res. 85:643-650.

10. Silver, R.B., et al. 2004. Mast cells: a unique source of renin. Proc. Natl. Acad. Sci. U. S. A. 101:13607-13612.

11. Mackins, C.J., et al. 2006. Cardiac mast cell-derived renin promotes local angiotensin formation, norepinephrine release, and arrhythmias in ischemia/reperfusion. J. Clin. Invest. 116:1063-1070. doi:10.1172/JCI25713.

12. Galli, S.J., et al. 2005. Mast cells as a "tunable" effector and immunoregulatory cells: recent advances. Annu. Rev. Immunol. 23:749-786.

13. Peti-Peterdi, J., Fintha, A., Fuson, A.L., Tousson, A., and Chow, R.H. 2004. Real-time imaging of renin release in vitro. Am. J. Physiol. 287:F329-F335. 
14. Kurtz, A., and Wagner, C. 1999. Cellular control of renin secretion. J. Exp. Biol. 202:219-225.

15. Nguyen, M., et al. 2002. Receptors and signaling mechanisms required for prostaglandin E2-mediated regulation of mast cell degranulation and IL- 6 production. J. Immunol. 169:4586-4593.

16. Tilley, S.L., et al. 2003. Identification of A3 receptor- and mast cell-dependent and -independent components of adenosine-mediated airway responsiveness in mice. J. Immunol. 171:331-337.

17. Juillerat, L., et al. 1990. Determinants of angioten$\sin$ II generation during converting enzyme inhibition. Hypertension. 16:564-572.

18. Urata, H., Kinoshita, A., Misono, K.S., Bumpus,
F.M., and Husain, A. 1990. Identification of a highly specific chymase as the major angiotensin IIforming enzyme in the human heart. J. Biol. Chem. 265:22348-22357.

19. Jenne, D.E., and Tschopp, J. 1991. Angiotensin II-forming heart chymase is a mast-cell-specific enzyme. Biochem. J. 276:567-568.

20. Nataraj, C., et al. 1999. Angiotensin II regulates cellular immune responses through a calcineurindependent pathway. J. Clin. Invest. 104:1693-1701.

21. Theoharides, T.C., and Cochrane, D.E. 2004. Critical role of mast cells in inflammatory diseases and the effect of acute stress. J. Neuroimmunol. 146:1-12.

22. Constantinides, P. 1995. Infiltrates of activated mast cells at the site of coronary atheromatous erosion or rupture in myocardial infarction [editorial]. Circulation. 92:1083.

23. Kovanen, P.T., Kaartinen, M., and Paavonen, T. 1995. Infiltrates of activated mast cells at the site of coronary atheromatous erosion or rupture in myocardial infarction. Circulation. 92:1084-1088.

24. Laine, P., et al. 1999. Association between myocardial infarction and the mast cells in the adventitia of the infarct-related coronary artery. Circulation. 99:361-369.

25. Hara, M., et al. 2002. Evidence for a role of mast cells in the evolution to congestive heart failure. J. Exp. Med. 195:375-381.

\title{
Pathomechanisms in rheumatoid arthritis - time for a string theory?
}

\author{
Cornelia M. Weyand and Jörg J. Goronzy
}

Kathleen B. and Mason I. Lowance Center for Human Immunology, Department of Medicine, Emory School of Medicine, Atlanta, Georgia, USA.

\begin{abstract}
RA is a quintessential autoimmune disease with a growing number of cells, mediators, and pathways implicated in this tissue-injurious inflammation. Now Kuhn and colleagues have provided convincing evidence that autoantibodies reacting with citrullinated proteins, known for their sensitivity and specificity as biomarkers in RA, enhance tissue damage in collagen-induced arthritis (see the related article beginning on page 961). This study adds yet another soldier to the growing army of autoaggressive mechanisms that underlie RA. With great success researchers have dismantled the pathogenic subunits of RA, adding gene to gene, molecule to molecule, and pathway to pathway in an ever more complex scheme of dysfunction. The complexity of the emerging disease model leaves us speechless. It seems that with this wealth of data available, we need to develop a new theory for this disease. We may want to seek guidance from our colleagues in physics and mathematics who have successfully integrated their knowledge of elementary particles and the complexity of their interacting forces by formulating the string theory.
\end{abstract}

Most scientists agree that simplicity is beautiful, alluding to the fact that true understanding of a natural phenomenon is reached when it can be expressed as a simple formula. Albert Einstein led the physicists in the ultimate quest for a theory that would provide a comprehensive description of the laws of nature. Witnessing the growing complexity of physics, Einstein believed that there was a need for a "unified field theory" and was convinced that it would bring the beauty of general relativity to all of nature's laws.

Einstein did not succeed, but in the last 3 decades a theory called string theory has gained

Nonstandard abbreviations used: anti-CCP, anticyclic citrullinated peptide; CII, bovine type II collagen.

Conflict of interest: The authors have declared that no conflict of interest exists.

Citation for this article: J. Clin. Invest. 116:869-871 (2006). doi:10.1172/JCI28300. momentum, promising that it can provide a unified theory of all the elementary particles and their interactions incorporating Einsteinian gravitation and other fields (1). If physicists are coming closer to obtaining a theory that describes all laws of nature, does that raise hope for us that an understanding of

\section{Horror autotoxicus - autoantibodies in RA}

The first immune abnormality described in patients with RA was the production of autoantibodies, so-called "rheumatoid factors," directed against the constant region of $\operatorname{IgG}(2)$. Fifty years ago it seemed reasonable to hypothesize that the patients' dilemma was indeed a scenario of horror autotoxicus. Rheumatoid factors became critically important as diagnostic tools, but why they were generated and how precisely such a complex puzzle as RA is within reach? they participated in synovitis remained less well defined. The question of whether rheumatoid factors are pathogenic or are instead an epiphenomenon of chronic autoimmune disease has plagued the field of rheumatology for several decades.

The description of antibodies to citrullinated proteins, first identified as anti-perinuclear factor and anti-keratin antibodies, has revived some of these discussions $(3,4)$. Anti-cyclic citrullinated peptide (anti-CCP) antibodies appear to be rather sensitive $(68 \%$ sensitivity) and highly specific (98\% specificity) for RA (5). These autoantibodies were first seen as binding reactivity to filaggrin, a protein that is not expressed in the synovium and is typically found during terminal differentiation of epithelial cells. However, other proteins, such as fibrin, that have undergone posttranslational citrullination could serve as a target in the joint and thus represent the arthritogenic antigen recognized by pathogenic autoantibodies.

\section{Anti-CCP antibodies - a disease amplifier}

In an elegant study published in the current issue of the JCI, Kuhn and colleagues (6) have examined the pathogenic role of anti-CCP antibodies in an animal model of autoimmune arthritis. Arthritis was induced in mice by immunization with bovine type II collagen (CII). Immunization not only led to the production of anti-CII antibodies but also induced anti-CCP antibodies. Interestingly, both types of autoantibodies could be detected prior to frank 